\title{
Maternal and Infant Death and the rVSV-ZEBOV Vaccine Through Three Recent Ebola Virus Epidemics-West Africa, DRC Équateur and DRC Kivu: 4 Years of Excluding Pregnant and Lactating Women and Their Infants from Immunization
}

\author{
David A. Schwartz ${ }^{1}$ \\ Published online: 26 November 2019 \\ (C) The Author(s) 2019
}

\begin{abstract}
Purpose of Review Ebola virus infection has one of the highest overall case fatality rates of any viral disease. It has historically had an especially high case mortality rate among pregnant women and infants - greater than $90 \%$ for pregnant women in some outbreaks and close to $100 \%$ in fetuses and newborns. The Merck recombinant vaccine against Ebola virus, termed rVSV-ZEBOV, underwent clinical trials during the 2013-2015 West Africa Ebola epidemic where it was found to be $100 \%$ efficacious. It was subsequently used during the 2018 DRC Équateur outbreak and in the 2018 DRC Kivu Ebola which is still ongoing, where its efficacy is $97.5 \%$. Pregnant and lactating women and their infants have previously been excluded from the design, clinical trials, and administration of many vaccines and drugs. This article critically examines the development of the rVSV-ZEBOV vaccine and its accessibility to pregnant and lactating women and infants as a life-saving form of prevention through three recent African Ebola epidemics-West Africa, DRC Équateur, and DRC Kivu.

Recent Findings Pregnant and lactating women and their infants were excluded from participation in the clinical trials of rVSVZEBOV conducted during the West Africa epidemic. This policy of exclusion was continued with the occurrence of the DRC Équateur outbreak in 2018, in spite of calls from the public health and global maternal health communities to vaccinate this population. Following the onset of the DRC Kivu epidemic, the exclusion persisted. Eventually, the policy was reversed to include vaccination of pregnant and lactating women. However, it was not implemented until June 2019, 10 months after the start of the epidemic, placing hundreds of women and infants at risk for this highly fatal infection.

Summary The historical policy of excluding pregnant and lactating women and infants from vaccine design, clinical trials, and implementation places them at risk, especially in situations of infectious disease outbreaks. In the future, all pregnant women, regardless of trimester, breastfeeding mothers, and infants, should have access to the Ebola vaccine.
\end{abstract}

Keywords Vaccine $\cdot$ Vaccination $\cdot \mathrm{rVSV}-Z E B O V \cdot$ Ebola virus $\cdot$ Ebola vaccine $\cdot$ West Africa Ebola epidemic $\cdot$ Équateur province Ebola outbreak $\cdot$ Kivu Ebola epidemic $\cdot$ Maternal death $\cdot$ Fetal death $\cdot$ Human rights $\cdot$ Pregnancy complications $\cdot$ Immunization $\cdot$ DRC Ebola epidemics · Exclusion of pregnant women

This article is part of the Topical Collection on Vaccines in Pregnant Women and Infants

David A. Schwartz

davidalanschwartz@gmail.com

1 Medical College of Georgia, Augusta University, 1950 Grace Arbor Court, Atlanta, GA 30329, USA

\section{Introduction}

The case fatality rate (CFR) for Ebola virus is one of the highest of any infectious disease $[1,2]$. The initial outbreak of the Ebola virus disease (EVD) occurred in the town of Yambuko, Democratic Republic of the Congo (DRC, then called Zaire) in late August of 1976. During that outbreak, 318 people were infected and a shocking 280 died - a CFR of $88 \%$ over 11 weeks [3•]. In a pattern that was to be repeated 
in subsequent outbreaks, a high percentage of caregivers at the rural Yambuko Mission Hospital also became infected with the previously unknown virus -13 of the 17 hospital staff members (76\%) developed the infection and $11(80 \%)$ died [3•]. At about the same time, the World Health Organization (WHO) announced that another outbreak of a similar hemorrhagic fever was occurring in southern Sudan, centered in Nzara, between June and November 1976 [4]. Of 284 persons with EVD during the Sudanese outbreak, the overall CFR was $53 \%$. In 1979, a recurrent but smaller outbreak occurred in the same area of Sudan, resulting in 34 infections and 22 deathsa 65\% CFR [5].

Since that time, multiple outbreaks of EVD had occurred, with the largest being the 2013-2015 West African Ebola epidemic, which began in Guinea and moved across the borders to Liberia and Sierra Leone, eventually resulting in an official case count of 28,616 infected persons and 11,310 deaths [6]. The approximate overall CFR was $40 \%$, although it is generally believed that these metrics understated both the numbers of infected persons as well as deaths from EVD during this epidemic [1, 7]. In August 2015, an experimental vaccine for the Ebola virus, the rVSV-ZEBOV produced by Merck, became available as part of a cluster-randomized clinical trial for persons at risk during the West African Ebola epidemic [8]. Family members and other contacts of infected persons, healthcare givers, and persons in contact with the bodies of EVD victims were all eligible for receiving the new vaccine-all, that is, except for pregnant and lactating women and their infants. The theoretical risk that the replication competent vaccine virus could cross the placenta and harm the fetus or cause other complications to the mother resulted in their exclusion from receiving the vaccine-in this case, with a disease that had a high maternal mortality rate and an essentially $100 \%$ case fatality rate among infected fetuses and newborns [9-12].

In 2018, Ebola reemerged in the country in which it was first recognized - two back-to-back outbreaks began in the DRC. The first occurred in Équateur province of northwestern DRC, lasting from May until June. When the end of the outbreak was declared on July 24th, there had been a total of 38 confirmed and 16 probable EVD infections, 33 deaths, and a CFR of $61 \%$ [13]. Although greater than 2 years had passed since the final case in West Africa was reported, during the Équateur province outbreak the rVSV-ZEBOV vaccine was administered but pregnant and lactating women and infants were still excluded. The second, and significantly larger, EVD epidemic began at the start of August 2018 in North Kivu province [14]. This epidemic is still continuing, has infected 3296 persons and caused 2194 deaths [15], and is the second most widespread since the discovery of the virus in 1976. Once again, the rVSV-ZEBOV was administered to persons at risk but excluded pregnant and lactating women and infants less than 1 year of age until June 2019 [16, 17].
The intentional exclusion of pregnant and lactating women and their infants from both the clinical trials and subsequent distribution of this vaccine has remained controversial through all three Ebola epidemics $[9,10,16,18,19,20 \bullet, 21-27,28 \cdot \bullet]$. This article discusses the scientific, public health, organizational, and humanitarian issues surrounding the withholding of this highly effective immunization from this population at high risk for infection, and future policy directed to the rights of pregnant women and their infants to receive life-saving vaccines.

\section{Mortality of Ebola Virus Infection Among Non-vaccinated Pregnant Women and Their Infants}

There is no evidence that women who are pregnant are more biologically susceptible to becoming infected with Ebola virus than are non-pregnant individuals [1, 7, 9, 29]. However, both prior to and during the West Africa Ebola virus epidemic, it was generally believed that once a pregnant woman acquired Ebola infection, she was more likely to have a fatal outcome than were non-pregnant persons [7], and that based upon prior outbreaks that greater than $90 \%$ of infected pregnant women and $100 \%$ of fetuses would likely die as a result of EVD [1, 29]. In an interview performed early in the epidemic, a representative from a non-governmental organization had opined that the survival rate for expectant mothers was virtually zero [30]. In a report published in 2015 [31], the probability for maternal and infant survival of EVD was summarized as follows,

\section{"Present data suggests that maternal mortality remains high (approximately 95\%) and peri-natal mortality vir- tually $100 \%$ for infected pregnant women."}

During the initial EVD outbreak in Yambuku, ten live infants were born to mothers who subsequently died of the infection. All of these children also died within 19 days [9, 20•]. Analysis of all EVD outbreaks prior to the West Africa epidemic by Bebell revealed that there were 111 cases of pregnant women reported who had acquired the infection, with an aggregate CFR of $86 \%$ [7]. The highest maternal and infant CFRs reported for EVD occurred during the 1995 outbreak in Kikwit, Zaire, in which only 1 of 15 EVD-infected women survived (CFR 93\%) [19]. However, it should be noted that all of these women were probably infected via injection with contaminated needles and that this parenteral route of transmission is hypothesized to have contributed to the high CFR. All of the pregnant women during the Kikwit EVD outbreak presented with severe hemorrhage. In addition to maternal mortality, 10 women $(66 \%)$ had spontaneous abortions, and one woman 
delivered a premature stillborn infant. Four of the pregnant women died during the third trimester. The single survivor among this group had a curettage because of an incomplete abortion after 8 months of amenorrhea [32].

Garba et al. [33] reviewed the published results from 12 studies that were performed both prior to the West African epidemic and during it. They found data on the clinical outcomes of 108 pregnant women with EVD in five countries-Guinea, Sierra Leone, DRC, Liberia, and Uganda. These include six case reports, two crosssectional studies, three retrospective studies, and one technical report. Among all countries and outbreaks, they found that 91 of the 108 pregnant women died-a CFR of $84.3 \%$. In addition to maternal death, pregnant women with EVD are at high risk for having a spontaneous abortion and stillbirth, as well as pregnancy-related hemorrhage $[1,7]$.

Recently, in a retrospective evaluation of outcome data from the West African epidemic, the authors found no evidence to support a significant difference in CFRs between pregnant women with suspected or confirmed EVD compared to non-pregnant women [34].

\section{Development of the Ebola rVSV-ZEBOV Vaccine}

The recombinant, replication-competent, vesicular stomatitis virus-based vaccine (VSV-EBOV, also known as rVSV-ZEBOV) was the result of extensive research in mouse models, followed in 2005 by testing in cynomolgus macaques. Vaccination with rVSV-ZEBOV was found to protect cynomolgus macaques from lethal challenges of Ebola virus following intramuscular and aerosol routes [35]. Using mouse-adapted Ebola virus in the murine model, mice were found to be completely protected from lethal challenge up to 28 days following intranasal, intramuscular, and intraperitoneal vaccination with rVSVZEBOV [36]. In the macaque model, both intramuscular, oral, and intranasal administration of the vaccine completely protected macaques against lethal doses of Ebola virus. These studies suggested that the efficacy of the vaccine was independent of the route of administration [37]. Rodent models were used to examine the durability of the protective effect of the vaccine. The results were excellent-mice were completely protected from lethal Ebola virus challenge up to 9 months following vaccination with rVSV-ZEBOV [36, 38], and guinea pigs were protected for as long as 18 months after vaccination [38]. These results demonstrated the pre-exposure efficacy of the experimental vaccine as well as its ability to produce a durable antigen-specific immune response in immunized animals. Next, follow-up studies were performed showing that mice, guinea pigs, and hamsters developed partial or complete protection when vaccinated shortly before an infectious challenge [37]. When rhesus macaques were inoculated with rVSV-ZEBOV from 20 to $30 \mathrm{~min}$ following a lethal viral challenge, they developed a febrile illness; however, one-half of the animals survived, thus demonstrating a partial post-exposure efficacy of rVSV-ZEBOV in nonhuman primates [39]. It was also demonstrated that crossprotection existed for the rVSV-ZEBOV vaccine between different strains within the Zaire ebolavirus species [35, 40]. Given the concerns existing for possible pre-existing immunity to the VSV vaccine vector, studies were performed with macaques that had been previously vaccinated with VSVLASV (a recombinant VSV-Lassa fever vaccine) - the results indicated that presence of antibodies specific to the VSV vector had no effect on the protective efficacy of later VSV-based vaccination [41]. Further animal testing was performed to ensure that the VSV wild-type (VSVwt) virus used to make the replicating vaccine had no neurotropic effects [42].

Although the first human clinical trials of the rVSVZEBOV vaccine were not to begin until the West African epidemic, they might unintentionally have started sooner. An outbreak of Marburg virus, a filovirus closely related to Ebola virus with identical symptomatology [1], began in Angola in October 2014. As a member of the international relief effort, Dr. Steven Jones, a Canadian microbiologist who was an important member of the team that developed the Ebola vaccine, arrived in Angola. Although rVSV-ZEBOV had not yet been tested in humans, it had demonstrated efficacy in preventing Ebola and Marburg virus infections in mice, so Dr. Jones and his team brought vials of the experimental vaccine with them in case of an accidental infection [43]. Fortunately, it was not needed in Angola, and the vaccine waited until the West Africa epidemic for its initial testing in humans.

\section{3-2015 West African Ebola Epidemic: First Use of the Recombinant Ebola Vaccine, but Pregnant and Lactating Women and Their Infants Were Excluded}

At the beginning of the West Africa Ebola epidemic, there were no effective or approved antiviral therapeutic agents or vaccines available to treat filovirus infections - the clinical management of Ebola and Marburg virus infections in all previous outbreaks had consisted of supportive care. These included administration of fluids and electrolytes, maintaining adequate blood pressure, analgesia, usage of blood products, and clinical management of coagulopathy, secondary infections, and other conditions [9]. It was during this epidemic, however, that specific antiviral compounds and vaccines became available for the first time for experimental testing or, in some cases, for compassionate use. There were vaccines that 
were in the early stages of development and evaluation, but only a few had entered the phase I stage of testing for safety, immunogenicity, and efficacy [35, 40, 44]. In April 2014, shortly after the epidemic began, a panel of experts was organized by the WHO to discuss potential forms of treatment [45] - they decided that unregistered interventions were acceptable for human use if laboratory and animal testing had produced positive results. This expert panel [45] also advised that investigators had

"a moral duty to also evaluate these interventions for treatment or prevention, in the best possible clinical trials in order to definitely prove their safety and efficacy or to provide evidence to stop their utilization."

Importantly, the panel recognized the unique status of pregnant women and children with EVD infection [20• 44, 45] and stated

"children and pregnant women should be considered particularly vulnerable [because of their higher mortality rates]... and given special protection when receiving such interventions"

As the epidemic progressed and the fatalities increased, numerous proposals for clinical trials were submitted to the WHO Research Ethics Review Committee (WHO-ERC), the committee that evaluated and approved proposed potential clinical investigations including new and amended protocols for experimental interventional (drug, vaccine) and observational studies [44].

One of the most difficult decisions faced by the committee members in designing, approving, and implementing the drug and vaccine protocols was the question of pregnant women and children [44]. All proposed studies of drugs and vaccines that were submitted to WHO-ERC had excluded pregnant women [20•]. However, it was recognized that exclusion of pregnant women and children from drug and vaccine trials undermined ethical principles of justicefairness, equity, and maximization of benefit. In addition, exclusion of these groups from clinical trials would deny them the potential life-saving benefits from an infection with a high CFR, at the time believed to be $100 \%$ in fetuses and neonates and approximately $90 \%$ in pregnant women [9]. These mortality data were of great significance in evaluating the risk/benefit relationship in enrolling pregnant women and infants in clinical trials. This problematic situation was addressed in by the WHO Ethics Working Group meeting 20-21 October 2014 [46],

"It is ethically important to ensure that vulnerable populations such as pregnant women and those with diminished autonomy such as children or those with mental incapacities are not arbitrarily excluded from trials. Instead their inclusion into clinical trials should be guided by a risk benefit analysis and the ability to secure adequate consent."

Clinical outcomes and mortality metrics from previous epidemics showing the high CFR for pregnant women and the almost certain deaths of their fetuses and newborns led the WHO committee to support the inclusion of pregnant women together with their fetuses in the planned clinical trials of both drugs and vaccines. This decision was based not only upon the incredibly high mortality rates that were expected in both mothers, fetuses, and neonates, but also because pregnant mothers had a greater interest in and right to decide their own fate and the fate of their unborn children than did administrators, sponsors, investigators, or committee members, and pregnant women should be granted the same rights for decision-making as non-pregnant women [20•].

During the period from August 2014 to April 2016, WHOERC examined 24 new EVD-protocols and 22 amendments [44]. All of the protocols for vaccine clinical trials excluded pregnant and lactating women. The proposed clinical trials for two promising antiviral drugs - brincidofovir and favipiraviralso excluded women who were pregnant for a variety of reasons (potential embryotoxicity for brincidofover and lack of insurance coverage for favipiravir) [20•]. The WHO-ERC systematically requested amendments to these protocols in order to include pregnant women and children. Despite the efforts by the WHO-ERC as well as the MSF Ethics Review Board and Inserm Institutional Review Board to have the applicants reconsider their excluding pregnant women, the need for rapid implementation of the trials in the field took priority over the delays that would have been encountered in pursuing revision of the protocols to include pregnant women $[20 \bullet, 44]$. An openlabel, cluster-randomized ring vaccination trial (Ebola ça suffit!, translated as "Ebola that's enough!"), of rVSV-ZEBOV was initiated in the communities of Conakry and eight surrounding prefectures in the Basse-Guinee region of Guinea, and in Tomkolili and Bombali in Sierra Leone. The pilot phase of the trial began on March 23rd, 2015, and ring enrollment was concluded on January 20th, 2016 [47••]. When the clinical trial of Merck rVSV-ZEBOV demonstrated protective effects in non-pregnant adults, and the WHO-ERC and Data Safety Monitoring Board requested that pregnant women receive the vaccine, 42 pregnant women were denied participation in the trial $[20 \bullet, 47 \bullet \bullet$.

Enrollment of pregnant women into clinical trials and their gaining access to potentially life-saving drugs and vaccines was challenging in spite of the obvious risk/benefit considerations. In some cases, pharmaceutical corporations that were manufacturing the products would simply not permit their administration to women who were pregnant, or the insurers would not provide insurance for pregnant women [12]. By the 
end of the West African epidemic, pregnant women, their fetuses, and newborns had been systematically excluded from all drug and vaccine clinical trials $[9,19]$. Eventually, pregnant women did gain access to favipiravir, but only following extensive negotiations between the manufacturer and Médecins Sans Frontières. The sole surviving newborn with EVD, Baby Nubia, received her treatment with ZMapp outside of the clinical trial [12].

Interestingly, a situation arose during the Ebola Phase 3 cluster-randomized ring vaccination trial in Guinea (Ebola ça suffit!) where 23 pregnant women were inadvertently administered the rVSV-ZEBOV vaccine. This resulted from pregnancy tests not being routinely performed, and the identification of a woman's pregnancy status based upon selfreporting $[20 \bullet, 47 \bullet \bullet]$. The results of their outcomes have not been published, the sample size is small for statistical analysis, and there was some loss of clinical follow-up, but preliminary data indicate that these women did not have significant differences in pregnancy loss as compared with vaccinated women who were not pregnant [48]. Additional data on the effects of the rVSV-ZEBOV vaccine among immunized pregnant women were obtained from the Sierra Leone Trial to Introduce a Vaccine against Ebola (STRIVE), a randomized, unblinded phase $2 / 3$ trial conducted in 2015. Although exclusion criteria included current pregnancy (pregnancy testing was required for all women $<50$ years old) and breastfeeding, 104 pregnancies occurred among 103 women (43 vaccinated, 60 unvaccinated) with an estimated onset within 2 months following vaccination or enrollment [49]. Among women with known pregnancy outcomes, there were no significant differences between vaccinated and non-vaccinated mothers.

\section{Ebola Outbreak in Équateur Province, DRC-Pregnant Women and Infants Remain Excluded from Vaccination}

On May 3rd, 2018, a new outbreak of EVD developed in the Équateur province of northwestern DRC - it was the 9th outbreak of Ebola to occur in that country [50]. Provincial health authorities reported that 17 persons had developed EVD near Bikoro, a small market town lying on Lake Tumba south of Mbdanka, near the neighboring Republic of the Congo. The index case was a police officer-after his funeral, 11 members of his family developed the infection, of whom 7 had provided care for him or attended his funeral. On 17 May, the first case of EVD was reported from Mbadanka, the capital city of Équateur province and a bustling port city of over one million persons located on the Congo River. This was the first time that Ebola virus had reached a city in the DRC, and it rekindled fears of when Ebola virus had reached urban areas during the West African epidemic. In addition, there was worry that Ebola virus could spread via river traffic to the capital city of Kinshasa, a city of approximately 11 million, as well as to Brazzaville, both of which lie on the Congo River, and then across national borders to nine other countries as well [19]. Fortunately, rVSV-ZEBOV was available, becoming the first time that the Ebola vaccine, donated by Merck, was distributed early in the course of an EVD outbreak. Ring fence vaccinations were quickly organized in the affected areas - using this method, contacts of those infected, followed by contacts of those contacts, were vaccinated, as were health care workers, laboratory personnel, surveillance workers, and people involved with burials. Unfortunately, the restrictive policies of exclusion of pregnant and lactating women and infants that had been maintained during the West Africa epidemic were once again implemented, excluding them from receiving the potentially lifesaving vaccine [19]. By the close of the epidemic on 24 July 2018, there were 54 confirmed or suspected cases and 33 deaths with a CFR of $61 \%$. A total of 3330 persons received the rVSV-ZEBOV vaccine during the outbreak [51] —none of them pregnant or under 1 year of age.

\section{Kivu Ebola Epidemic Begins in DRC - and Pregnant Women and Their Infants Were Still Excluded from Receiving the rVSV-ZEBOV Vaccine}

Just 1 week following the close of the Équateur province outbreak, Ebola returned to a different region of the DRC [52]. A woman from Mangina, a town in North Kivu district in the northeastern part of the country, had been seen at a local health center on July 19th, 2018 for a cardiac condition and died at home with symptoms of hemorrhagic fever on July 25th. Several members of her family subsequently developed the same symptoms, dying soon afterwards [19,53]. A team of investigators found an additional six cases, and following confirmation of the disease as Ebola virus, an outbreak was declared on August 1st, 2018. Unlike the prior nine Ebola outbreaks in DRC, the Kivu region was especially problematic from the standpoint of epidemiological surveillance, medical intervention, and control. North Kivu province is densely populated, borders Uganda to the east and Rwanda to the south, and is an active conflict zone. The Kivu conflict had been ongoing since 2004, with more than 100 armed groups operating in this region [53]. Violence and crime are common, and there are intensive military operations ongoing - the administrative center of the district, Beni, is under military rule. The presence of "red zones" - areas that are inaccessible to public health workers due to fighting and the risk of kidnapping - prevented health workers from working where surveillance and treatment were needed. This was the first EVD outbreak occurring in a war zone, where armed rebel militias constituted an ever-present threat to epidemic control personnel. Vaccination using the rVSV-ZEBOV vaccine was begun on August 8th and a ring vaccination program was implemented 
in an attempt to stop spread of transmission. In this programsimilar to that used in the Équateur province Ebola outbreakthe rVSV-ZEBOV vaccine was offered to contacts of known cases and the contacts of contacts, including any individual over 1 year of age - except pregnant and lactating women. The DRC Ministry of Health, together with WHO and other partners, decided that pregnant and lactating women would, once again, be excluded from receiving rVSV-ZEBOV, the only Ebola vaccine to have completed efficacy testing. Within the public health community, the decision to withhold vaccination was considered by many to be indefensible, especially given that there had never been a mother-infant pair that had survived EVD [18, 19, 27]. Three public health experts from Johns Hopkins University [18] wrote

"The rVSV-ZEBOV vaccine will give pregnant women, and the children they are carrying, a chance to live. Without it, most of the pregnant women infected with Ebola, and almost all of their infants, will die".

At meeting of the WHO's Strategic Advisory Group of Experts (SAGE) on Immunization in Geneva in October 2018, there was a discussion of development of candidate Ebola vaccines and the progress in implementing of the "expanded access and compassionate use" vaccine protocol in the DRC, but no recommendation for immunizing pregnant women was made. Also at this meeting, a review of available data for rVSV-ZEBOV was commissioned, based upon clinical outcomes from those women who had been inadvertently vaccinated in early pregnancy or women who became pregnant shortly after being immunized [48]. At this time, SAGE did not believe that there existed sufficient data to issue a definitive recommendation whether women should be offered the vaccine, and instead deferred to local DRC authorities to determine the ongoing Ebola immunization strategy. As the outbreak continued to rapidly spread, by November 2018, the infection was reported in two provinces (North Kivu and Ituri) and 14 health zones. Surveillance data revealed that there was a predominance of women who were becoming infected, especially in the reproductive age group [18]. Women of child-bearing potential were not the only persons that were significantly affected - children made up greater than one-third of all Ebola infections [54], with 1 in 10 cases of EVD occurring in children less than 5 years of age. As of January 12th, 2019, a total of 595 confirmed and 49 probable cases of EVD had occurred in 16 health zones in DRC, with a CFR of $58 \%$ among confirmed cases - a total of 59,453 persons had received the rVSV-ZEBOV vaccine, none of them pregnant or less than 1 year of age [55]. As the epidemic continued and expanded during the start of 2019, there were additional calls to reassess the policy of excluding pregnant and lactating women and their infants from receiving vaccination $[19,56]$.

\section{Pregnant Women in Kivu Ebola Epidemic Are Approved to Receive the Vaccine, but It Remains Withheld}

In late January 2019, the DRC National Institute for Biomedical Research initiated revising the vaccination protocol to include pregnant and lactating women within Ebola contact rings in ongoing immunization efforts. This action was endorsed and supported by WHO SAGE at their meeting in Beijing on February 20th, 2019. SAGE was now in support of pregnant and breastfeeding women and infants receiving the Ebola vaccine [57-59], noting that

"In view of the severity of the outbreak and aligned with SAGE's recommendation from October 2018 [1], SAGE welcomes and supports the recent recommendation of the ethics committee of DRC to also authorize the vaccination of pregnant women in outbreak affected areas, using the currently recommended vaccination strategies, with the live-replicating rVSV-ZEBOV-GP vaccine with informed consent and in compliance with GCP. As recommended by the ethics committee, every effort must be made to collect data on the safety of the vaccine in these populations, including a documentation of the pregnancy outcomes. SAGE advises that the use of rVSV- ZEBOV-GP vaccine in pregnant women currently remains limited to the EVD outbreak affected areas in DRC and should be continuously evaluated based on the emerging data on the safety and efficacy of the vaccine in this target population".

At the time of this decision, there were 773 confirmed cases, 65 probable cases, and 534 deaths; $57 \%$ of the confirmed and probable EVD cases were female, and $61 \%$ of them were of child-bearing age $[57,58]$. This announcement was met with great approval from the public health community [17, 59], where it was hoped that it would provide an example for the inclusion of pregnant women in the design and clinical trials of vaccines that were in development for such infections as Zika virus and Lassa virus [56, 60]. But the vaccine was not administered.

\section{The Ebola Vaccine Is Finally Administered to Pregnant Women in DRC}

Despite this landmark decision, and with the continued spread of the epidemic, pregnant and lactating women and their infants were still not given the rVSV-ZEBOV vaccine [61]. During the period from Nov 26th, 2018 to May 26th, 2019, 319 pregnant women and 603 lactating women were registered as Ebola contacts but had been denied the vaccine [17, 61]. In June 2019, the outbreak reached 2000 cases with 1339 
deaths - it was the 2nd largest outbreak of Ebola infection in history. The rapidity of spread and transmission dynamics of the epidemic were evidenced by the fact that it took 8 months to reach 1000 infection persons, but only 71 days to infect another thousand individuals [17]. Delay in starting the vaccination of pregnant women and infants was due to modifications of the immunization protocol that were requested by the DRC's National Ethics Committee [16]. This months-long delay in vaccinating put hundreds of pregnant women and their fetuses at risk. According to Professor Steve Ahuka, Director of Virology at DRC's National Institute of Biomedical Research, these modifications included women in their first trimester of pregnancy being excluded from vaccination. Dr. Ahuka said [16],

"The vaccination of pregnant women is usually a very complex decision to make, especially ... when they are using a new vaccine which is still under a trial."

On June 2nd, 2019-almost 4 months after the process to amend the protocol to include pregnant women was initiated by SAGE - the DRC Ministry of Health announced that the National Ethics Committee at the School of Public Health at the University of Kinshasa had finally approved an amendment to the vaccination protocol that would permit the administration of the Merck rVSV-ZEBOV vaccine to pregnant women beyond their first trimester of pregnancy and to lactating women if they were identified as case contacts. The committee still maintained that only children over the age of 6 should be vaccinated [16, 17]. It had taken over 4 years for pregnant and breastfeeding women to receive EVD vaccination since the initial clinical trials. The first pregnant women finally received the rVSV-ZEBOV vaccine on June 13th-almost 10 months after the outbreak began [16]. According to Dr. Carleigh Krubiner, a Policy Fellow at the Center for Global Development [16],

"Hopefully this will set a new precedent for ongoing and future Ebola vaccination efforts, avoiding costly delays in protocol approvals while women face the very real threats of Ebola infection."

As of early October 2019, over 840 pregnant women in the Ebola outbreak zone of DRC have received the rVSVZEBOV vaccine [62]. On October $12^{\text {th }}$, the DRC's technical committee (CMRE) announced that vaccination will begin in November 2019 in Goma, the capital city of North Kivu province, using a newly developed $2^{\text {nd }}$ vaccine, a prime boost product known as Ad26.ZEBOV/MVA-BN made by the Janssen Pharmaceutical Division of Johnson \& Johnson, in order to increase supply and test its effectiveness [63].

\section{Conclusions}

Beginning with the first EVD outbreak in 1976, infected pregnant women had an extremely high mortality rate-in some cases greater than $90 \%$ - with an almost $100 \%$ case fatality rate among their fetuses and infants. During the development, clinical trials and subsequent deployment of the Merck rVSVZEBOV vaccine for the Ebola virus, pregnant and lactating women, as well as their infants, were excluded from receiving the life-saving immunization. rVSV-ZEBOV was introduced during the West Africa Ebola epidemic, and then used extensively in two subsequent DRC outbreaks, but pregnant and lactating women and infants continued to be excluded from receiving the vaccine. As criticism of this policy increased from the public health community, pregnant women were finally permitted to receive the vaccine 10 months after the Kivu Ebola epidemic began. It is hoped that the lessons learned from excluding pregnant and lactating women and infants in vaccine development, testing and implementation will provide guidance for the development and accessibility of future vaccines.

Acknowledgments The author expresses his gratitude to Dr. Carleigh Krubiner of the Center for Global Development and Johns Hopkins Berman Institute of Bioethics for her valuable comments.

\section{Compliance with Ethical Standards}

Conflict of Interest David A. Schwartz declares that he has no conflict of interest.

Human and Animal Rights and Informed Consent This article does not contain any studies with human or animal subjects performed by any of the authors.

Open Access This article is distributed under the terms of the Creative Commons Attribution 4.0 International License (http:// creativecommons.org/licenses/by/4.0/), which permits unrestricted use, distribution, and reproduction in any medium, provided you give appropriate credit to the original author(s) and the source, provide a link to the Creative Commons license, and indicate if changes were made.

\section{References}

Papers of particular interest, published recently, have been highlighted as:

- Of importance

• Of major importance

1. Schwartz DA. Maternal filovirus infection and death from Marburg and Ravn viruses: Highly lethal to pregnant women and their fetuses similar to Ebola Virus. In: Okware SI, editor. Re-emerging filovirus diseases. London: IntechOpen; 2019. ISBN: 978-1-78985550-0. Available from: https://www.intechopencom/online-first/ maternal-filovirus-infection-and-death-from-marburg-and-ravn- 
viruses-highly-lethal-to-pregnant-women. Accessed 20 August 2019.

2. Bebell LM. Ebola virus disease and pregnancy: Perinatal transmission and epidemiology. In: Schwartz DA, Anoko JN, Abramowitz $\mathrm{S}$, editors. Pregnant in the time of Ebola: Women and their children in the 2013-2015 West African epidemic. New York: Springer Nature; 2019. p. 53-65. ISBN-13: 978-3319976365.

3. Breman JG, Heymann DL, Lloyd G, McCormick JB, Miatudila M, Murphy FA, et al. Discovery and description of Ebola Zaire virus in 1976 and relevance to the west African epidemic during 20132016. J Infect Dis. 2016;214(Suppl 3): S93-101. Doi: https://doi. org/10.1093/infdis/jiw207 available from: https://www.ncbi.nlm. nih.gov/pme/articles/PMC5050466/. accessed 25 July 2019. A detailed description of the initial outbreak of Ebola virus disease in 1976 in Yambuku, DRC and its relation to the West Africa Ebola epidemic.

4. WHO/International Study Team. Ebola haemorrhagic fever in Sudan, 1976. Report of a WHO/International Study Team. Bull World Health Organ. 1978;56(2):247-70 Available from: https:// www.ncbi.nlm.nih.gov/pmc/articles/PMC2395561/. Accessed 1 September 2019.

5. CDC. Ebola virus disease distribution map: Cases of Ebola virus disease in Africa Since 1976. 2019. Available from: https://www. cdc.gov/vhf/ebola/history/distribution-map.html. Accessed 27 July 2019.

6. CDC. Ebola virus disease. Case counts. 2019. Available from: https://www.cdc.gov/vhf/ebola/history/2014-2016-outbreak/casecounts.html?CDC_AA_refVal=https\%3A\%2F\%2Fwww.cdc. gov $\% 2$ Fvhf $\% 2$ Febola $\% 2$ Foutbreaks $\% 2$ F2014-west-africa $\%$ 2Fcase-counts.html. Accessed 27 July 2019.

7. Bebell LM, Oduyebo T, Riley LE. Ebola virus disease and pregnancy: A review of the current knowledge of Ebola virus pathogenesis, maternal, and neonatal outcomes. Birth Defects Res. 2017;109(5):353-62. https://doi.org/10.1002/bdra.23558 Available from: https://onlinelibrary.wiley.com/doi/full/10.1002/ bdra.23558\#bdr223558-bib-0022. Accessed 30 July 2019.

8. Henao-Restrepo AM, Longini IM, Egger M, Dean NE, Edmunds WJ, Camacho A, et al. Efficacy and effectiveness of an rVSVvectored vaccine expressing Ebola surface glycoprotein: interim results from the Guinea ring vaccination cluster-randomised trial. Lancet. 2015;386(9996):857-66. https://doi.org/10.1016/S01406736(15)61117-5 Available from: Accessed 1 September 2019.

9. Schwartz, D.A. Maternal and infant survival following Ebola infection -Their exclusion from treatment and vaccine trials and "Primum non nocere". In: Pregnant in the Time of Ebola: Women and Their Children in the 2013-2015 West African Epidemic. D.A. Schwartz, J.A. Anoko, S. Abramowitz, editors. New York: Springer Nature; 2019. Pgs. 147-155 ISBN-13: 978-3319976365.

10. Caluwaerts S, Bayliss F. An Ebola survivor orphaned by vaccine policy. Impact Ethics. 25 November 2016. Available from: https:// impactethics.ca/2016/11/25/nubia-an-ebola-survivor-orphaned-byvaccine-policy/

11. Chappell B. New Ebola vaccine has ' 100 percent' effectiveness in early results. NPR. The Two-Way. 31 July 2015. Available from: https://www.npr.org/sections/thetwo-way/2015/07/31/428018501/ new-ebola-vaccine-has-100-percent-effectiveness-in-early-results. Accessed July 29, 2019.

12. Caluwaerts S. Nubia's mother: being pregnant in the time of experimental vaccines and therapeutics for Ebola. Reprod Health. 2017;14(Suppl 3):157. https://doi.org/10.1186/s12978-017-0429-8 Available from: https:/www.ncbi.nlm.nih.gov/pmc/articles/ PMC5751508/. Accessed 19 July 2019.

13. WHO. Situation report: declaration of the end of the Ebola outbreak in Équateur Province. 25 July 2018. Available from: https://apps. who.int/iris/bitstream/handle/10665/273348/SITREP_EVD_ DRC_20180725-eng.pdf?ua=1. Accessed 6 September $20 \overline{19}$.
14. WHO. Cluster of presumptive Ebola cases in North Kivu in the Democratic Republic of the Congo. 1 August 2018. Available from: https://www.who.int/news-room/detail/01-08-2018-cluster-ofpresumptive-ebola-cases-in-north-kivu-in-the-democratic-republicof-the-congo. Accessed 6 September 2019.

15. World Health Organization. Ebola Dashboard RDC. 15 November 2019. Available from: http://who.maps.arcgis.com/apps/ opsdashboard/index.html\#/e70c3804f6044652bc37cce7d8fcef6c. Accessed 18 November 2019.

16. Higgins A. Pregnant women in DRC finally receive Ebola vaccine. DEVEX. 28 June 2019. Available from: https://www.devex.com/ news/pregnant-women-in-drc-finally-receive-ebola-vaccine95204. Accessed 4 September 2019.

17. Soucheray S. Ebola hits 2,000 cases as vaccine OK'd in some pregnant, lactating women. CIDRAP. 3 June 2019. Available from: http://www.cidrap.umn.edu/news-perspective/2019/06/ebola-hits2000-cases-vaccine-okd-some-pregnant-lactating-women. Accessed 25 July 2019.

18. Faden R, Karron R, Krubiner C. An 'indefensible' decision: not vaccinating pregnant and lactating women in an Ebola outbreak. STAT. 27 August 2018. Available from: https://www.statnews.com/ 2018/08/27/ebola-vaccine-pregnant-lactating-women/. Accessed 15 July 2019.

19. Schwartz DA. Clinical trials and administration of Zika virus vaccine in pregnant women: Lessons (that should have been) learned from excluding immunization with the Ebola vaccine during pregnancy and lactation. Vaccines (Basel). 2018;6(4). https://doi.org/10. 3390/vaccines6040081 Available from: https://www.mdpi.com/ 2076-393X/6/4/81/htm. Accessed 29 August 2019.

20. Gomes MF, de la Fuente-Núñez V, Saxena A, Kuesel AC. Protected to death: systematic exclusion of pregnant women from Ebola virus disease trials. Reprod Health. 2017;14:172. https://doi.org/10.1186/ s12978-017-0430-2 Discusses the CFRs for pregnant women, fetuses and neonates from previous outbreaks, criteria for inclusion into vaccine trials, and the consequences of exclusion for pregnant women and their infants.

21. Rasmussen SA, Jamieson DJ. Ebola vaccine for pregnant women: one step closer but still more to go. STAT. 13 June 2019. Available from: https://www.statnews.com/2019/06/13/ebola-vaccinepregnant-lactating-women-2/. Accessed 18 July 2019.

22. Higgins A. A landmark policy reversal in Congo will now allow pregnant women to receive the Ebola vaccine. The Lily. Washington Post. 25 February 2019. Available from: https://www. thelily.com/a-landmark-policy-reversal-in-congo-will-now-allowpregnant-women-to-receive-the-ebola-vaccine/. Accessed 3 September 2019.

23. Smith J. Exclusion of pregnant women from vaccine research, deployment is 'unacceptable,' health and bioethics experts say. HUB. Johns Hopkins University. 10 December 2018. Available from: https://hub.jhu.edu/2018/12/10/pregnant-women-vaccineexclusion-bioethics/. Accessed 1 September 2019.

24. Furneaux R. Vaccine studies still exclude pregnant women. That's a big mistake. Just ask the women living in fear of Ebola. Mother Jones. 18 December 2018. Available from: https://www. motherjones.com/politics/2018/12/vaccine-studies-still-excludepregnant-women-thats-a-big-mistake/. Accessed 26 July 2019.

25. Krubiner CB, Faden RR, Karron RA, Little MO, Lyerly AD, Abramson JS, et al. Pregnant women \& vaccines against emerging epidemic threats: Ethics guidance for preparedness, research, and response. Vaccine. 2019. https://doi.org/10.1016/j.vaccine.2019. 01.011.

26. Lovell D. In the fight against Ebola in the Congo, pregnant women must not be forgotten. Medical Xpress. 31 August 2018. Available from: https://medicalxpress.com/news/2018-08-ebola-congopregnant-women-forgotten.html. Accessed 5 September 2019. 
27. Branswell H. Experts call for reversing the decision to deny the Ebola vaccine to pregnant women. STAT. 27 August 2018. Available from: https://www.statnews.com/2018/08/27/expertscall-for-reversing-denial-of-ebola-vaccine-to-pregnant-women/. Accessed 1 September 2019.

28.• The PREVENT Working Group. Pregnant women \& vaccines against emerging epidemic threats: Ethics guidance for preparedness, research, and response. Baltimore, MD: September 2018. Available from: https://static1.squarespace.com/static/ $574503059 f 72665$ be $88193 \mathrm{e} 9 / \mathrm{t} / 5 \mathrm{c} 082429 \mathrm{c} 2241 \mathrm{ba} 2553 \mathrm{ee} 1 \mathrm{f5} /$ 1544037418944/PREVENT-Web.pdf. Accessed 15 June 2019. The PREVENT Working Group makes important recommendations for improving access to vaccines by pregnant women during outbreaks of emerging infections, and for their consideration and inclusion in research, development and clinical trials.

29. Black BO, Caluwaerts S, Achar J. Ebola viral disease and pregnancy. Obstet Med. 2015;8(3):108-13. https://doi.org/10.1177/ 1753495X15597354 Available from: https:/www.ncbi.nlm.nih. gov/pmc/articles/PMC4582839/. Accessed 29 July 2019.

30. Reuters. Ebola clinic for pregnant women opens. Pregnant women survival rate from the virus is virtually zero. Philly Voice. 12 January 2015. Available from: https://www.phillyvoice.com/ ebola-clinic-pregnant-women-opens/. Accessed 7 September 2019.

31. RCOG. Principles of management for pregnant women with Ebola: A Western context. n.d. . Available from: https://www.rcog.org.uk/ globalassets/documents/news/ebola-and-pregnancy-western.pdf. Accessed 20 July 2019.

32. Mupapa K, Mukundu W, Bwaka MA, Kipasa M, De Roo A, Kuvula K, et al. Ebola hemorrhagic fever and pregnancy. J Infect Dis. 1999;179(Suppl 1):S11-2. https://doi.org/10.1086/514289.

33. Garba I, Dattijo LM, Habib AG. Ebola virus disease and pregnancy outcome: A review of the literature. Trop J Ob Gynecol. 2017;34(1):6-10. https://doi.org/10.4103/TJOG.TJOG_3_17 Available from: http://www.tjogonline.com/article.asp?issn=01895117 ; year $=2017$; volume $=34 ;$ issue $=1 ;$;page $=6$; epage $=10$; aulast $=$ Garba. Accessed 3 September 2019.

34. Henwood PC, Bebell LM, Roshania R, Wolfman V, Mallow M, Kalyanpur A, et al. Ebola virus disease and pregnancy: A retrospective cohort study of patients managed at 5 Ebola treatment units in West Africa. Clin Infect Dis. 2017;65(2):292-9. https://doi.org/10. 1093/cid/cix290 Available from: https://www.ncbi.nlm.nih.gov/ pmc/articles/PMC5850452/. Accessed 7 September 2019.

35. Jones SM, Feldmann H, Stroher U, Geisbert JB, Fernando L, Grolla A, et al. Live attenuated recombinant vaccine protects nonhuman primates against Ebola and Marburg viruses. Nat Med. 2005;11: 786-90. https://doi.org/10.1038/nm1258.

36. Jones SM, Stroher U, Fernando L, Qiu X, Alimonti J, Melito P, et al. Assessment of a vesicular stomatitis virus-based vaccine by use of the mouse model of Ebola virus hemorrhagic fever. J Infect Dis. 2007;196(Suppl 2):S404-12. https://doi.org/10.1086/520591.

37. Suder E, Furuyama W, Feldmann H, Marzi A, de Wit E. The vesicular stomatitis virus-based Ebola virus vaccine: From concept to clinical trials. Hum Vaccin Immunother. 2018;14(9):2107-13. https://doi.org/10.1080/21645515.2018.1473698 Available from: https://www.ncbi.nlm.nih.gov/pmc/articles/PMC6183239/\# CIT0007. Accessed 3 September 2019.

38. Wong G, Audet J, Fernando L, Fausther-Bovendo H, Alimonti JB, Kobinger GP, et al. Immunization with vesicular stomatitis virus vaccine expressing the Ebola glycoprotein provides sustained long-term protection in rodents. Vaccine. 2014;32:5722-9. https:// doi.org/10.1016/j.vaccine.2014.08.028

39. Feldmann H, Jones SM, Daddario-DiCaprio KM, Geisbert JB, Stroher U, Grolla A, et al. Effective post-exposure treatment of Ebola infection. PLoS Pathog. 2007;(3):e2. https://doi.org/10. 1371/journal.ppat.0030002 Available from: https://www.ncbi.nlm. nih.gov/pmc/articles/PMC1779298/. Accessed 14 September 2019.

40. Qiu X, Fernando L, Alimonti JB, Melito PL, Feldmann F, Dick D, et al. Mucosal immunization of cynomolgus macaques with the VSVDeltaG/ZEBOVGP vaccine stimulates strong Ebola GPspecific immune responses. PLoS One. 2009;(4):e5547. https:// doi.org/10.1371/journal.pone.0005547 Available from: https:// www.ncbi.nlm.nih.gov/pmc/articles/PMC2678264/. Accessed 1 September 2019.

41. Marzi A, Feldmann F, Geisbert TW, Feldmann H, Safronetz D. Vesicular stomatitis virus-based vaccines against Lassa and Ebola viruses. Emerg Infect Dis. 2015;21:305-7. https://doi.org/10.3201/ eid2102.141649 Available from: https://www.ncbi.nlm.nih.gov/ pmc/articles/PMC4313664/. Accessed 1 September 2019.

42. Mire CE, Miller AD, Carville A, Westmoreland SV, Geisbert JB, Mansfield KG, et al. Recombinant vesicular stomatitis virus vaccine vectors expressing filovirus glycoproteins lack neurovirulence in nonhuman primates. PLoS Negl Trop Dis. 2012;6(3):e1567. https://doi.org/10.1371/journal.pntd.0001567 Available from: https://www.ncbi.nlm.nih.gov/pmc/articles/PMC3308941/. Accessed 1 September 2019.

43. Pinchin K. Ebola vaccine is a story of missed opportunity. PBS Frontline. 13 August 2019. Available from: https://www.pbs.org/ $\mathrm{wgbh} /$ frontline/article/behind-the-life-saving-ebola-vaccine-is-astory-of-missed-opportunity/. Accessed 9 September 2019.

44. Alirol E, Kuesel AC, Guraiib MM, de la Fuente-Núñez V, Saxena A, Gomes MF. Ethics review of studies during public health emergencies - the experience of the WHO ethics review committee during the Ebola virus disease epidemic. BMC Med Ethics. 2017;18: 43. https://doi.org/10.1186/s12910-017-0204-y Available from: https://www.ncbi.nlm.nih.gov/pmc/articles/PMC5485606/. Accessed 3 September 2019.

45. WHO. Ethical considerations for use of unregistered interventions for Ebola virus disease. Report of an advisory panel to WHO. 2014. Available from: https://www.who.int/csr/resources/publications/ ebola/ethical-considerations/en/. Accessed 10 September 2019.

46. WHO. Ethical issues related to study design for trials on therapeutics for Ebola virus disease. October 2014. Available from: https:// www.who.int/csr/resources/publications/ebola/ethical-evdtherapeutics/en/. Accessed 10 September 2019.

47.• Henao-Restrepo AM, Camacho A, Longini IM, Watson $\mathrm{CH}$, Edmunds WJ, Egger M, et al. Efficacy and effectiveness of an rVSV-vectored vaccine expressing Ebola surface glycoprotein: Interim results from the Guinea ring vaccination clusterrandomised trial (Ebola Ça Suffit!). Lancet. 2017;389(10068): 505-18. https://doi.org/10.1016/S0140-6736(16)32621-6 Available from: https://www.thelancet.com/journals/lancet/article/ PIIS0140-6736(16)32621-6/fulltext. Accessed 13 August 2019. Describes the experimental design and results of the initial open-label, cluster-randomized ring vaccination trial of the rVSV-ZEBOV vaccine in Guinea and Sierra Leone during the West Africa Ebola epidemic.

48. Edmunds J, Jarvis C. Benefits risk analysis of vaccination of pregnant women with rVSV-ZEBOV as part of an expanded access programme. October 2018. Available from: https://www.who.int/ immunization/sage/meetings/2018/october/SAGE_october_2018_ ebola_Edmunds_Jarvis.pdf. Accessed 12 October 2019.

49. Samai M, Seward JF, Goldstein ST, Mahon BE, Lisk DR, Widdowson MA, et al. The Sierra Leone trial to introduce a vaccine against Ebola: An evaluation of rVSV $\triangle$ G-ZEBOV-GP vaccine tolerability and safety during the West Africa Ebola outbreak. J Infect Dis. 2018;217(suppl 1):S6-S15. https://doi.org/10.1093/infdis/ jiy020 Available from: https://www.ncbi.nlm.nih.gov/pmc/ articles/PMC5961340/. Accessed 14 October 2019.

50. European Centre for Disease Control and Prevention. Ebola virus disease outbreak in Equateur Province, Democratic Republic of the 
Congo. 25 May 2018. Available from: https://ecdc.europa.eu/sites/ portal/files/documents/17-05-2018-RRA-first-update-Ebola\% 20haemorrhagic\%20fever-Democratic\%20Republic\%20of\% 20the\%20Congo.pdf. Accessed 8 September 2019.

51. Leonard K. Health officials contain Ebola's spread in the Congo. Washington Examiner. 6 July 2018. Available from: https://www. washingtonexaminer.com/policy/healthcare/health-officialscontain-ebolas-spread-in-the-congo. Accessed 2 September 2019.

52. WHO. Ebola virus disease Democratic Republic of the Congo. External Situation Report 13. 30 October 2018. Available from: http://apps.who.int/iris/bitstream/handle/10665/275658/SITREP EVD_DRC_20181030-eng.pdf?ua=1. Accessed 1 September 2019.

53. Médecins Sans Frontières. New Ebola outbreak declared in North Kivu. 5 September 2018. Available from: https://www.msf.org/ new-ebola-outbreak-declared-north-kivu.

54. UNICEF. Children account for more than one third of Ebola cases in eastern Democratic Republic of the Congo - UNICEF. 11 December 2018. Available from: https://www.unicef.org/wca/ press-releases/children-account-more-one-third-ebola-caseseastern-democratic-republic-congo-unicef. Accessed 11 September 2019.

55. WHO. Weekly bulletin on outbreaks and other emergencies. 11 January 2019. Available from: https://apps.who.int/iris/bitstream/ handle/10665/279455/OEW02-0511012019.pdf. Accessed 8 September 2019.

56. Karron R, Krubiner C, Faden F. As the world prepares to fight Lassa fever, the interests of pregnant women must be part of the planning. STAT. 15 January 2019. Available from: https://www. statnews.com/2019/01/15/lassa-fever-vaccine-pregnant-women/. Accessed 8 September 2019.
57. UN News. Pregnant, nursing women can now be given Ebola vaccine, UN health agency announces. 21 February 2019. Available from: https://news.un.org/en/story/2019/02/1033281. Accessed 10 September 2019.

58. WHO. SAGE interim recommendations on vaccination against Ebola virus disease (EVD). 20 February 2019. Available from: https://www.who.int/immunization/interim_ebola recommendations_feb_2019.pdf. Accessed 10 September 2019.

59. Branswell $\mathrm{H}$. Ebola vaccine will be provided to women who are pregnant, marking reversal in policy. STAT. 20 February 2019. Available from: https://www.statnews.com/2019/02/20/ebolapregnancy-reversal/. Accessed 20 August 2019.

60. das Neves Almeida R, Racine T, Magalhães KG, Kobinger GP. Zika virus vaccines: Challenges and perspectives. Vaccines (Basel). 2018;6(3). https://doi.org/10.3390/vaccines6030062 Available from: https://www.ncbi.nlm.nih.gov/pmc/articles/ PMC6161012/. Accessed 15 August 2019.

61. Rasmussen SA, Jamieson DJ. Ebola vaccine for pregnant women: one step closer but still more to go. STAT. 13 June 2019. Available from: https://www.statnews.com/2019/06/13/ebola-vaccinepregnant-lactating-women-2/. Accessed 25 August 2019.

62. Krubiner CB, Schwartz DA. Viral hemorrhagic fevers in pregnant women and the vaccine landscape: Comparisons between yellow fever, Ebola, and Lassa fever. Curr Trop Med Rep. 2019;6(4) in press.

63. Schnirring L. As Ebola cases climb, launch of 2nd vaccine in works. CIDRAP. 14 October 2019. Available from: http://www. cidrap.umn.edu/news-perspective/2019/10/ebola-cases-climblaunch-2nd-vaccine-works. Accessed 15 October 2019.

Publisher's Note Springer Nature remains neutral with regard to jurisdictional claims in published maps and institutional affiliations. 